\title{
Effect of Different Predrying Treatments on Physicochemical Quality and Drying Kinetics of Twin Layer Solar Tunnel Dried Tomato (Lycopersicon esculentum L.) Slices
}

\author{
Lelise Tilahun Dufera ${ }^{\mathbb{D}},{ }^{1}$ Werner Hofacker, ${ }^{2}$ Albert Esper, ${ }^{3}$ and Oliver Hensel ${ }^{4}$ \\ ${ }^{1}$ Department of Post-Harvest Management, Jimma University, P.O.Box 307, Jimma, Ethiopia \\ ${ }^{2}$ Institute of Applied Thermo and Fluid Dynamics, Konstanz University of Applied Sciences, Konstanz D-78462, Germany \\ ${ }^{3}$ INNOTECH mbh, Stuttgart, Germany \\ ${ }^{4}$ Department of Agricultural Engineering, University of Kassel, Kassel, Germany
}

Correspondence should be addressed to Lelise Tilahun Dufera; lelisetilahun@gmail.com

Received 18 October 2021; Revised 21 December 2021; Accepted 5 January 2022; Published 1 February 2022

Academic Editor: Ali Noman

Copyright (C) 2022 Lelise Tilahun Dufera et al. This is an open access article distributed under the Creative Commons Attribution License, which permits unrestricted use, distribution, and reproduction in any medium, provided the original work is properly cited.

\begin{abstract}
In tomato drying, degradation in final quality may occur based on the drying method used and predrying preparation. Hence, this research was conducted to evaluate the effect of different predrying treatments on physicochemical quality and drying kinetics of twin-layer-solar-tunnel-dried tomato slices. During the experimental work, tomato slices of var. Galilea were used. As predrying treatments, $0.5 \%$ calcium chloride $\left(\mathrm{CaCl}_{2}\right), 0.5 \%$ ascorbic acid $\left(\mathrm{C}_{6} \mathrm{H}_{8} \mathrm{O}_{6}\right), 0.5 \%$ citric acid $\left(\mathrm{C}_{6} \mathrm{H}_{8} \mathrm{O}_{7}\right)$, and $0.5 \%$ sodium chloride $(\mathrm{NaCl})$ were used. The tomato samples were sliced to $5 \mathrm{~mm}$ thickness, socked in the pretreatments for ten minutes, and dried in a twin layer solar tunnel dryer under the weather conditions of Jimma, Ethiopia. Untreated samples were used as control. The moisture losses from the samples were monitored by weighing samples at $2 \mathrm{~h}$ interval from each treatment. SAS statistical software version 9.2 was used for analyzing data on the physicochemical quality of tomato slices in CRD with three replications. From the experimental result, it was observed that dried tomato slices pretreated with $0.5 \%$ ascorbic acid gave the best retention of vitamin $\mathrm{C}$ and total phenolic content with a high sugar/acid ratio. Better retention of lycopene and fast drying were observed in dried tomato slices pretreated with $0.5 \%$ sodium chloride, and pretreating tomatoes with $0.5 \%$ citric acid resulted in better color values than the other treatments. Compared to the control, pretreating significantly preserved the overall quality of dried tomato slices and increased the moisture removal rate in the twin layer solar tunnel dryer.
\end{abstract}

\section{Introduction}

Tomato (Lycopersicom esculantum L.) belongs to the family of Solanaceae and is one of the most widely consumed fresh vegetables in the world [1]. In Ethiopia, tomato is widely produced for both household consumption and income generation. Due to its processing potential and yields per hectare, it is one of the commodities among which the Government of Ethiopia has given priority for agro-industry development in the country [2]. According to FAOSTAT, [3] Ethiopia's tomato production in 2018 was 43816 tons harvested from 7089 hectares of land. But due to its perishable nature, excess produce goes to waste. According
Emana et al., [4] a quarter (25\%) of tomatoes produced in Ethiopia will be lost at the postharvest stage. Hence, introducing preservation technologies are vital to minimize the postharvest loss of tomato.

Among traditional techniques used in food preservation, drying is the most effective and practically applicable way of preserving foods to minimize postharvest losses [5]. It can be carried out by different methods, such as hot air drying, sun drying, vacuum drying, freeze-drying, and solar drying. Since the cost of energy is the largest cost factor in mechanical drying, scaling up renewable energy in drying should be promoted in support of countries' transition towards low carbon development [6]. 
There are several types of solar dryers designed all over the world. A twin layer solar tunnel dryer, which was designed and developed by the University of Hohenheim, Germany, has a capacity of drying more than two times the Hohenheim solar tunnel dryer with equal collector area. From our previous drying experiment in Jimma, Ethiopia, compared to sun drying, the dryer showed a good performance in terms of quality retention and drying time $[7,8]$. Tomato drying using environmentally friendly technologies like twin layer solar tunnel drying can be easily adapted in Ethiopia to reduce the losses and improve its utilization in food formulations. However, in tomato drying, degradation in final quality may occur based on the drying method used and predrying preparation of the product $[9,10]$. Therefore, it should be done in the way that will be least damaging to the quality.

Predrying treatment is an important operation commonly employed before drying to increase the drying rate and to maintain quality of the product, [11] and every crop has its own optimum conditions of pretreatment when drying [12]. Different studies showed that pretreating tomatoes with ascorbic acid, citric acid, sodium metabisulphite, sodium chloride, and calcium chloride can improve quality maintenance of tomato during drying $[1,10,13-15]$. These studies have given a particular attention to the evaluation of different predrying treatments on the physicochemical quality of tomato in different drying methods (sun, solar cabinet, hot air dryer, and freeze-dryer).

The novelty of this work is that even though the twin layer solar tunnel dryer is reported to have good performance to be used in Ethiopia for tomato drying, predrying treatments to be used for better quality retention and shorter drying time were not studied yet. Proper drying of tomato can result in a stable product with better quality $[1,10,13,15]$ when assisted with predrying treatments. Therefore, the objective of this research was to evaluate the effects of different predrying treatments $(0.5 \%$ calcium chloride $(\mathrm{CaCl} 2), 0.5 \%$ ascorbic acid (C6H8O6), $0.5 \%$ citric acid (C6H8O7), and $0.5 \%$ sodium chloride $(\mathrm{NaCl})$ ) on physicochemical quality and drying kinetics of tomato slices under twin layer solar tunnel drying conditions.

\section{Materials and Methods}

2.1. Twin Layer Solar Tunnel Dryer. The twin layer solar tunnel dryer, which was developed by Hohenheim Engineers at the University of Hohenheim Germany, was installed at Jimma University College of Agriculture and Veterinary Medicine located in Jimma zone, Ethiopia. The area is located in the southwest of the country and lies between $36^{\circ} 5^{\prime}$ E longitude and $7^{\circ} 42^{\prime} \mathrm{N}$ latitude. The dryer consists of a solar collector and a solar drying unit (Figure 1). The collector section is $8 \mathrm{~m}$ long, and the drying section is $16 \mathrm{~m}$ long. It has $2 \mathrm{~m}$ width and stands on a $0.8 \mathrm{~m}$ high brick plinth. Both the collector and tunnel are covered with UVstabilized polythene sheet (transmittance 88-90\%). A 24 volt DC (direct current) fan is installed to provide the required airflow at the air inlet of the solar collector. The collector is painted black, and the products are dried on 60 trays made from perforated aluminum having $0.81 \mathrm{~m}^{2}$ area each arranged in two layers loaded one over the other inside the dying unit. Easy loading and unloading of the materials is facilitated by opening one side of the plastic cover using a hand-operated pipe and crank arrangement.

2.2. Instrumentation. During the experimental work, temperature and relative humidity of the ambient air and air in the twin layer solar tunnel dryer were measured by a data logger (Testo, model 174, Germany) at $30 \mathrm{~min}$ interval.

\section{Sample Preparation and Experimental Drying Procedure}

Fresh tomatoes of Galilea variety were sorted and washed with water, sliced into $5 \mathrm{~mm}$ thickness, and treated with $0.5 \%$ calcium chloride $(\mathrm{CaCl} 2), 0.5 \%$ ascorbic acid (C6H8O6), $0.5 \%$ citric acid (C6H8O7), and $0.5 \%$ sodium chloride $(\mathrm{NaCl})$ for ten minutes before drying. Non-pretreated samples were used as control samples (Figure 2). The pretreated and control samples were dried in the twin layer solar tunnel dryer. The moisture loss from the tomato slices was monitored by weighing samples at two-hour interval during the entire drying task, and the drying curves were obtained.

\subsection{Data Analysis}

3.1.1. Experimental Drying Curves. The moisture content of tomato slices was determined using (equation (1)) with reference to the bone-dry weight of the slices by drying the samples at $105 \mathrm{C}$ for $24 \mathrm{~h}$ in the hot air oven (Biobase Model DHG-9203 (A), China) [16]:

$$
M_{w b}=\left(\frac{M_{i}-\mathrm{Mf}}{M_{i}}\right) 100,
$$

where $M_{\mathrm{wb}}$ is the moisture content (\%wb) at time $t$, $M_{i}$ initial sample weight $(\mathrm{g})$, and $M_{f}$ the bone-dry weight $(\mathrm{g})$ of the sample.

\subsubsection{Quality Analysis of Dried Tomato Slices}

Lycopene. Lycopene in the tomato samples was determined as described in [17] using hexane:ethanol:acetone $(2: 1: 1)$ $(\mathrm{v} / \mathrm{v})$ mixture. Briefly, $1 \mathrm{~g}$ of tomato sample powder was dissolved in $1 \mathrm{ml}$ of distilled water and vortexed in water bath (model HH-S4, China) at $30^{\circ} \mathrm{C}$ for $1 \mathrm{hr}$. Then, $8.0 \mathrm{ml}$ of the extraction solvent hexane, ethanol, and acetone (ratio 2: $1: 1)$ was added capped and vortexed again and incubated for sixty minutes in a dark place. Finally, $1 \mathrm{ml}$ of distilled water was added to each sample and vortexed and allowed to stand to separate into phases. A UV-Vis spectrophotometer (T80, Jiangsu, China) was used to read the absorbance of the upper layers at a wavelength of $503 \mathrm{~nm}$. The lycopene content of the samples was then calculated using the following equation: 


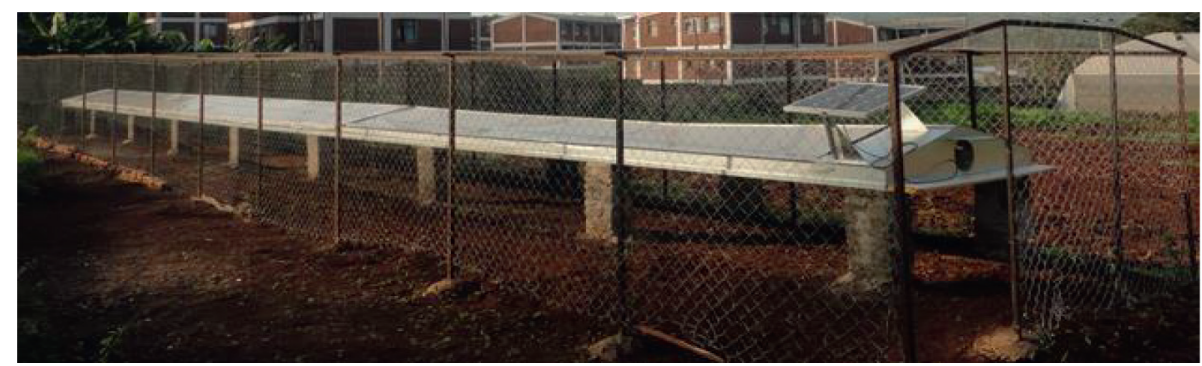

FIgURE 1: Photograph of the twin layer solar tunnel dryer.

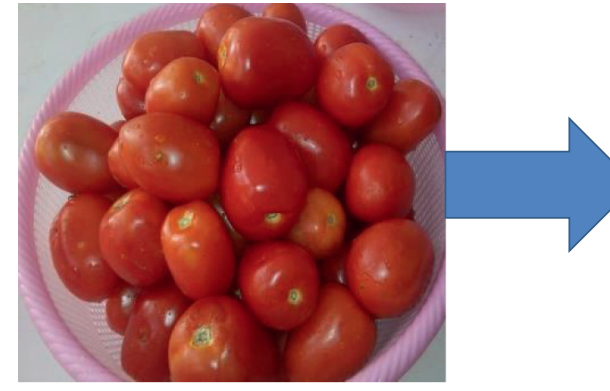

Fresh tomatoes
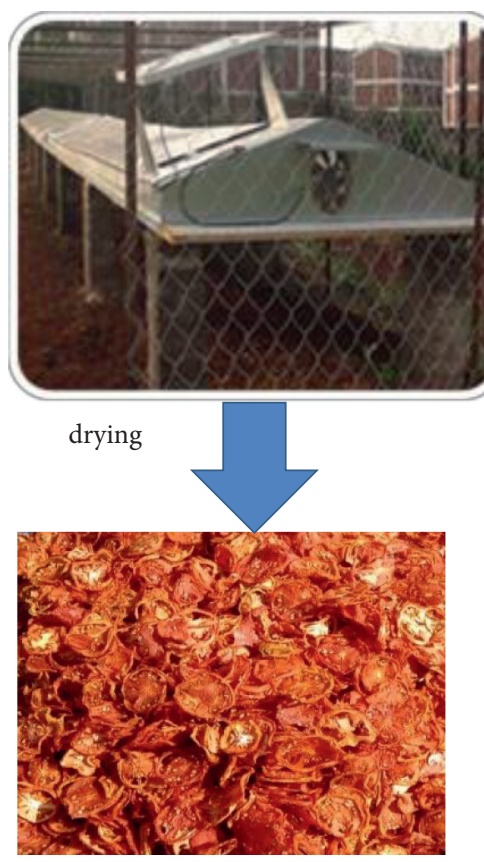

Dried tomato slices

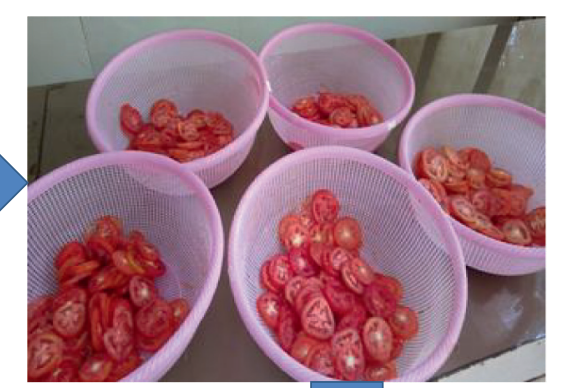

sliced tomatoes

FIgURE 2: Process flowchart of tomato drying with predrying treatments.

$$
\text { lycopene }\left(\frac{\mathrm{mg}}{100 \mathrm{~g} \mathrm{dw}}\right)=\mathrm{Abs}_{503 \mathrm{~nm}} \times 537 \times 8 \times \frac{0.55}{0.1} \times 172 \text {, }
$$

where $\mathrm{Abs}_{503 \mathrm{~nm}}$ is the absorbance at $503 \mathrm{~nm}, 537$ the lycopene molecular weight in $\mathrm{g} / \mathrm{mole}, 8$ the mixed solvent volume in $\mathrm{ml}, 0.55$ the volume ratio of the upper layer to the mixed solvents in $\mathrm{ml}, 55$ the ratio of volume of the upper layer to the mixed solvents in $\mathrm{ml}, 0.10$ the weight of tomato added in $\mathrm{g}$, and 172 the extinction coefficient for lycopene in hexane in $\mathrm{mM}^{-1}$

Vitamin C. AOAC [18] Official Method 967.21 was used to determine the vitamin $\mathrm{C}$ content of the samples. Briefly, $0.2 \mathrm{~g}$ of dried tomato powder was mixed in $40 \mathrm{ml}$ of $\mathrm{HPO}_{3}$ HOAc extracting solution (i.e., $15 \mathrm{~g}$ of $\mathrm{HPO}_{3}$ and $40 \mathrm{ml}$ of 
HOAc in $500 \mathrm{ml}$ of deionized $\mathrm{H}_{2} \mathrm{O}$ ). Standard solution was prepared to a final concentration of $10 \mathrm{mg}$ of ascorbic acid/ $100 \mathrm{ml}$. Then, $10 \mathrm{ml}$ of blank, test sample, and standard solution was titrated with the indophenol reagent (i.e., prepared by dissolving $42 \mathrm{mg}$ of $\mathrm{NaHCO}_{3}$ and $50 \mathrm{mg}$ of 2,6dichloroindophenol sodium salt in $200 \mathrm{ml}$ of deionized $\mathrm{H}_{2} \mathrm{O}$ ) to a light but distinctive rose pink endpoint lasting $\geq 5 \mathrm{sec}$. Vitamin $\mathrm{C}$ in $\mathrm{mg} / \mathrm{g}$ of the sample was then calculated using the following equation:

$$
\operatorname{vitamin} C\left(\frac{\mathrm{mg}}{\mathrm{gdw}}\right)=(X-B) \times\left(\frac{F}{E}\right) \times\left(\frac{V}{Y}\right),
$$

where $X$ is the average $\mathrm{ml}$ for test solution titration, $B$ the average $\mathrm{ml}$ for test blank titration, $F$ the $\mathrm{mg}$ ascorbic acid equivalents to $1.0-\mathrm{ml}$, indophenol standard solution, $E$ the sample weight $(\mathrm{g})$ or volume $V$ the volume of initial test solution in $\mathrm{ml}$, and $Y$ the volume of test solution titrated in $\mathrm{ml}$.

Total Phenolic Content. Total phenolic content was determined according to [19]. Briefly, $100 \mathrm{ml}$ methanol was used to mix $0.1 \mathrm{~g}$ of dried tomato powder. The mixture was then homogenized for $1 \mathrm{~min}$ in a homogenizer (POLYTRON 2500E, Switzerland). Then, $2.5 \mathrm{ml}$ of $2 \mathrm{~N}$ Folin-
Ciocalteu reagent and $2.5 \mathrm{ml}$ of $7.5 \%$ sodium carbonate solution were added to $0.5 \mathrm{ml}$ of methanolic solution of extracts and incubated for $45 \mathrm{~min}$ at $45^{\circ} \mathrm{C}$. Finally, the absorbance of the solution was measured at $765 \mathrm{~nm}$ using the UV-Vis spectrophotometer (T80 Jiangsu, China). To draw the calibration curve, gallic acid solution was prepared with $0,1,2,4,6,8,10,20,40,60,60,80$, and $100 \mathrm{mg} / \mathrm{L}$ gallic acid in methanol. Then, $2 \mathrm{ml}$ of $7.5 \%$ sodium carbonate and $2 \mathrm{~N}$ Folin-Ciocalteu reagent were added and mixed with $0.5 \mathrm{ml}$ of each gallic acid solution. The tubes were then covered with aluminum foil to stand for 30 minutes at room temperature, and the absorbance was measured at $765 \mathrm{~nm}$ using the UV/ Vis spectrophotometer (T80 Jiangsu, China). The measurement was compared to a standard curve $\left(R^{2}=98 \%\right)$ prepared with gallic acid solution. The total phenolic contents were then expressed as mg of gallic acid equivalents per gram of sample (mg GAE/g sample).

Titratable Acidity (TA). Titratable acidity was determined as described by [20] by titrating $10 \mathrm{ml}$ of the sample solution with sodium hydroxide $(0.1 \mathrm{~N})$ solutions to endpoint of pink color. The sample to be titrated was prepared by dissolving $5 \mathrm{~g}$ of dried tomato powder in 10-fold distilled water. Then, TA was calculated using the following equation:

$$
T A(\%)=\left(\frac{\mathrm{ml} \text { of } \mathrm{NaOH}(\text { titre }) \times 0.1 \mathrm{~N} \mathrm{NaOH} \times \text { acid meq.factor }}{\text { ml of juice titrated }}\right) \times 100 \text {. }
$$

Total Soluble Solid (TSS). Refractometer (model: DR20195, Germany) was used to measure TSS of the samples as described by Tefera et al. [21].

Water Activity $(a W)$. The water activities of samples were measured by an water activity meter (model: Novasina AG, $\mathrm{CH}-8853$ Lachen) at room temperature $\left(23.4 \pm 1^{\circ} \mathrm{C}\right)$.

Color. HTWG software was used for color analysis. Photographs of the samples were taken in a special chamber with a black background under controlled conditions. Then, chroma $(\mathrm{C})$, total color change $(\Delta \mathrm{E})$, and hue angle $\left(\mathrm{h}^{0}\right)$ were calculated as described in Wrolstad and Smith [22] using color parameters ( $a$ and $b, L$ ) obtained from the software:

$$
\begin{aligned}
\Delta E & =\left[\left(L-L_{o}\right)^{2}+\left(a-a_{o}\right)^{2}+\left(b-b_{o}\right)^{2}\right]^{1 / 2}, \\
\text { chroma } & =\left(a^{2}+b^{2}\right)^{1 / 2}, \\
\text { hue angle }\left(h^{o}\right) & =\tan ^{-1}\left(\frac{b}{a}\right) .
\end{aligned}
$$

Parameter $L^{*}$ represents the brightness of the color, $a^{*}$ the hue range of the colors red $(+)$ and green $(-)$, and $b *$ hue range of colors yellow $(+)$ and blue $(-)$.

Total color difference $(\Delta E)$ indicated the magnitude of color difference between fresh and dried tomato slices. Fresh tomatoes were used as the reference (Lo, ao, bo), and a larger $\Delta E$ denotes a greater color change from the reference material [23].
3.2. Experimental Design and Statistical Analysis. Completely randomized design (CRD) with one factor was used for the comparative evaluation of the effect of predrying treatments on the physicochemical quality of tomato slices. The factor is predrying treatments with five levels $(0.5 \%$ calcium chloride $\left(\mathrm{CaCl}_{2}\right), 0.5 \%$ ascorbic acid $\left(\mathrm{C}_{6} \mathrm{H}_{8} \mathrm{O}_{6}\right), 0.5 \%$ citric acid $\left(\mathrm{C}_{6} \mathrm{H}_{8} \mathrm{O}_{7}\right)$, and $0.5 \%$ sodium chloride $(\mathrm{NaCl})$, and untreated control) with three replications.

The effect of each predrying treatment on physicochemical quality (lycopene, vitamin C, total phenolic content, titratable acidity, total soluble solids, and water activity) of tomato slices was analyzed. Analysis of variance (ANOVA) was performed based on the procedures described by Gomez et al. [24] for each quality parameter. SAS statistical software version 9.2 was used for statistical analysis. The difference between treatment means was compared using Tukey's test at $5 \%$ probability level for characters having significant mean differences.

\section{Results}

4.1. Temperature and Relative Humidity of the Ambient Air and Air in the Solar Tunnel Dryer. During the experimental drying, the recorded maximum drying air temperature and the minimum relative humidity in the twin layer solar tunnel dryer were $68 \mathrm{C}$ and $1.8 \%$, respectively, whereas the maximum air temperature and the minimum relative humidity for the ambient air were $33.7 \mathrm{C}$ and $21 \%$, respectively (Figure 3). 
4.2. Quality of Dried Tomato Slices. In this work, statistically significant differences $(p<0.05)$ were observed in the lycopene content of pretreated tomato slices and untreated control during twin layer solar tunnel drying (Table 1). From the experimental result, a decrease in the lycopene content was observed in dried tomatoes compared to the fresh samples. Higher lycopene retention was observed in pretreated tomato samples than untreated ones. Lycopene content retention obtained for pretreated tomato samples was in the range of $41.39 \%-45.85 \%$, whereas lycopene content retention of untreated tomatoes was $26.57 \%$.

Better lycopene retention was observed in samples pretreated with sodium chloride followed by calcium chloride, ascorbic acid, and citric acid, respectively, than the untreated samples.

Drying condition is one of the several conditions that affect the degradation kinetics of ascorbic acid during drying [25]. In this study, vitamin $C$ contents in fresh tomatoes were decreased after drying and significant differences $(p<0.05)$ in the vitamin $C$ retention of tomato samples were observed among the treated and untreated samples after twin layer solar tunnel drying (Table 1). Higher vitamin $\mathrm{C}$ retention was obtained in pretreated tomato samples for all the treatments as compared to the control. Among the pretreatments used, $0.5 \%$ ascorbic acid-treated samples showed higher vitamin $\mathrm{C}$ retention followed by $0.5 \%$ citric acid and $0.5 \%$ sodium chloride.

The effect of predrying treatments on the total phenolic content (TPC) of twin-layer-solar tunnel-dried tomato slices is shown in Table 1. The initial TPC in the fresh tomatoes was decreased after drying for all treatments. From the result, it was observed that predrying treatments except $0.5 \%$ calcium chloride-pretreated samples showed significantly higher total phenolic content as compared to untreated control. From all treatments, citric acid (0.5\%)-pretreated samples showed the highest phenolic content followed by $0.5 \%$ ascorbic acid $(0.5 \%)$ and $0.5 \%$ sodium chloride $(0.5 \%)$ pretreated samples.

The total soluble solid content of tomatoes was significantly $(p \leq 0.05)$ increased after drying (Table 2$)$. The total soluble solids of fresh tomatoes were 5.3, whereas for the dried tomatoes, it was in the range of 7.43-9. Significant differences $(p \leq 0.05)$ were also observed in the total soluble solid content of pretreated and untreated tomato slices after drying. Compared to the untreated control samples, the pretreated ones showed higher TSS values. The result showed that the use of predrying treatments improved the TSS of the dried tomatoes. Total soluble solid content of the treated samples ranges between 8.2 and 9 , with a maximum value recorded in $0.5 \%$ citric acid-treated samples.

Titratable acidity (TA) of the dried tomatoes significantly $(p \leq 0.05)$ increased after drying (Table 2). In spite of the treatments used, an increase in titratable acidity was observed in pretreated tomato samples than the untreated control except the ascorbic acid-treated samples. The tomato samples pretreated with $0.5 \%$ ascorbic acid showed lower titratable acidity followed by $0.5 \%$ sodium chloride samples than the control. But samples pretreated with $0.5 \%$ citric acid and $0.5 \%$ calcium chloride showed a higher titratable acidity value than the control samples.

Water activities of the dried tomato with and without predrying treatments are shown in Table 2. Fresh tomatoes had a water activity of 0.95 , whereas the water activity of the dried samples ranged from 0.328 to 0.384 . Lower water activity values of $0.328,0.332$, and 0.336 were obtained for samples pretreated with $0.5 \%$ sodium chloride, $0.5 \%$ calcium chloride, and $0.5 \%$ citric acid, respectively, after 6 hours of drying.

Sugar/acid ratio (TSS/TA) has a significant role in the flavor of tomato [13]. In this experiment, the TSS/TA value of the tomato samples (both treated and untreated control) was decreased after drying (Table 2). The highest sugar/acid ratio was found in samples pretreated with $0.5 \%$ ascorbic acid followed by $0.5 \%$ sodium chloride $l, 0.5 \%$ calcium chloride, and $0.5 \%$ citric acid. The control samples exhibited a lower TSS/TA ratio compared to the treated samples.

Change in color values of dried tomato slices pretreated with different predrying treatments is shown in Table 3 . The results from this study showed that predrying treatments have effect on the color of the dried tomato slices. Lower overall color change $(\Delta E)$ was obtained for $0.5 \%$ citric acidtreated samples followed by $0.5 \%$ ascorbic acid-treated samples. From all treatments, relatively larger overall color change was observed in samples pretreated with $0.5 \%$ sodium chloride. Chroma values of the dried tomatoes were decreased for all pretreated tomatoes. A decrease in the $L$ value (brightness) was observed in all samples of dried tomato slices, and a small decrease was observed for $0.5 \%$ citric acid-treated samples. Better brightness retention of the pretreated samples was observed than the control. The lowest chroma change is observed for control samples followed by $0.5 \%$ ascorbic acid-treated samples. The hue angle $\left(h^{0}\right)$ of the pretreated tomato samples decreased after drying for all treatments except $0.5 \%$ citric acid-treated samples, and the highest decrease was obtained in $0.5 \%$ calcium chloride-pretreated samples.

4.3. Drying Curve of Moisture Content (\%wb) versus Time. Changes in the moisture content of tomato slices with drying time are shown in Figure 4. After $4 \mathrm{~h}$ of drying, the moisture contents of tomato slices were decreased from $95.62 \%$ to $20.57 \%, 96.1 \%$ to $29.5 \%, 95.68 \%$ to $16.59 \%, 95.65 \%$ to $17.8 \%$, and $95.81 \%$ to $38.82 \%$ in ascorbic acid, citric acid, sodium chloride, calcium chloride, and control samples, respectively. It was observed that pretreated tomato slices with $0.5 \%$ sodium chloride showed the highest decrease in moisture followed by $0.5 \%$ calcium chloride- and $0.5 \%$ ascorbic acid-pretreated tomatoes than the untreated control samples. In comparison with the pretreatments, control samples showed a lower decrease in the moisture content. This shows that pretreating tomato slices before drying shortens the drying time. 


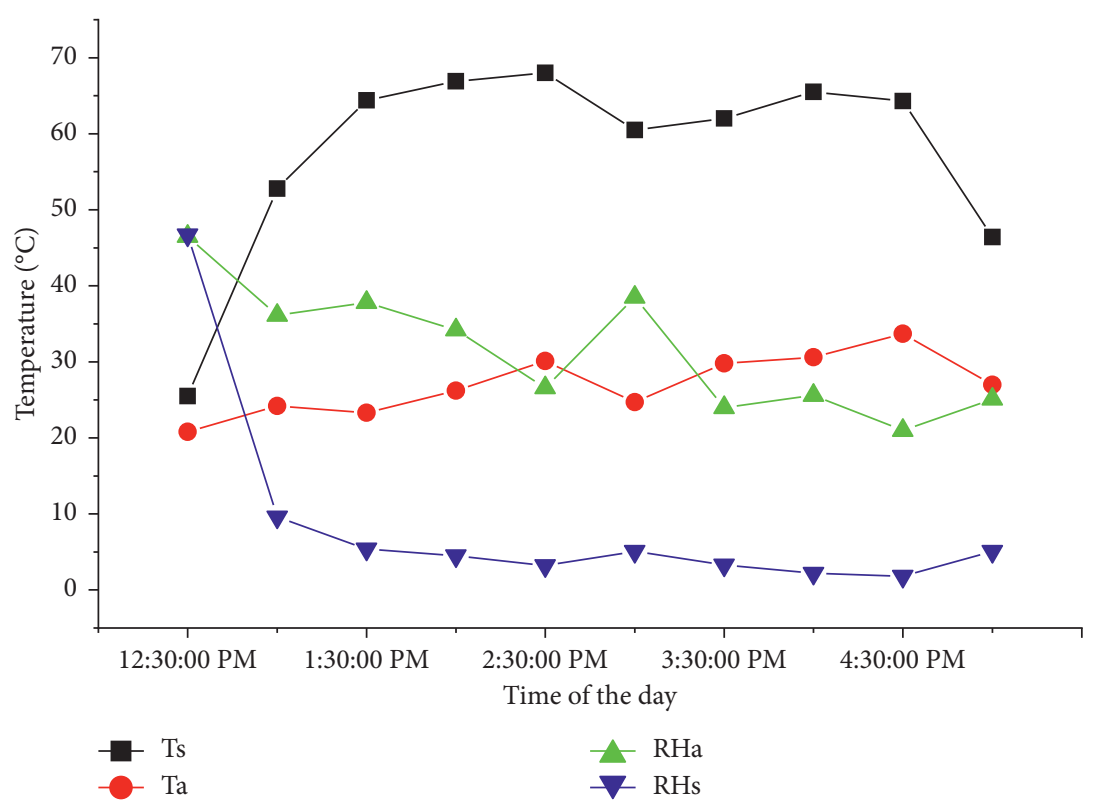

FIGURE 3: Variation in air temperature and relative humidity in the twin layer solar tunnel dryer and ambient air during drying. $\mathrm{Ts}=$ temperature of air in the twin layer solar tunnel dryer, Ta ambient air temperature, RHa $=$ relative humidity of ambient air, and $\mathrm{RH}=$ relative humidity of air in the twin layer solar tunnel dryer.

TABLE 1: Effect of predrying treatment on lycopene (mg/100 gDM), vitamin C, and total phenolic content of twin-layer-solar-tunnel-dried tomato samples.

\begin{tabular}{lccc}
\hline Treatments & Lycopene $(\mathrm{mg} / 100 \mathrm{gDM})$ & Vitamin C $(\mathrm{mg} / 100 \mathrm{~g} \mathrm{DM})$ & Total phenol $(\mathrm{mg}$ of GA/100 gDM) \\
\hline AA & $162.65^{\mathrm{c}} \pm 0.47$ & $266.67^{\mathrm{a}} \pm 17.93$ & $676.12^{\mathrm{ab}} \pm 16.22$ \\
CC & $174.09^{\mathrm{b}} \pm 0.31$ & $168.28^{\mathrm{cd}} \pm 8.96$ & $552.22^{\mathrm{c}} \pm 28.09$ \\
CA & $157.14^{\mathrm{d}} \pm 0.36$ & $217.47^{\mathrm{b}} \pm 7.76$ & $686.74^{\mathrm{a}} \pm 16.22$ \\
CO & $100.88^{\mathrm{e}} \pm 0.47$ & $152.75^{\mathrm{d}} \pm 4.48$ & $612.40^{\mathrm{cb}} \pm 32.44$ \\
SC & $178.67^{\mathrm{a}} \pm 0.64$ & $181.23^{\mathrm{c}} \pm 8.96$ & $654.88^{\mathrm{ab}} \pm 16.22$ \\
Fresh & 379.62 & 239.72 & 764.79 \\
CV & 0.27 & 5.37 & 4.00 \\
Lsd & 1.2 & 25.7 & 71.9 \\
\hline
\end{tabular}

Means with the same letter are not significantly different $(p>0.05)$ according to Tukey's (significant difference) test. AA: ascorbic acid; CC: citric acid; CA: calcium chloride; CO: control; SC: sodium chloride.

TABLE 2: Effect of predrying treatment on TSS, TA, Wa, and TSS/TA of twin-layer-solar-tunnel-dried tomato samples.

\begin{tabular}{lcccc}
\hline Treatments & TSS $\left({ }^{\circ}\right.$ Brix $)$ & TA $(\%)$ & Wa & TSS/TA \\
\hline AA & $8.9^{\mathrm{a}} \pm 0.1$ & $0.75^{\mathrm{d}} \pm 0.02$ & $0.384^{\mathrm{a}} \pm 0.005$ & $11.86^{\mathrm{a}} \pm 0.49$ \\
CC & $8.93^{\mathrm{a}} \pm 0.11$ & $0.904^{\mathrm{ab}} \pm 0.03$ & $0.332^{\mathrm{cd}} \pm 0.001$ & $9.88^{\mathrm{b}} \pm 0.19$ \\
CA & $9^{\mathrm{a}} \pm 0.00$ & $0.955^{\mathrm{a}} \pm 0.03$ & $0.336^{\mathrm{c}} \pm 0.001$ & $9.42^{\mathrm{bc}} \pm 0.29$ \\
CO & $7.43^{\mathrm{c}} \pm 0.23$ & $0.87^{\mathrm{cb}} \pm 0.05$ & $0.344^{\mathrm{b}} \pm 0.001$ & $8.56^{\mathrm{c}} \pm 0.75$ \\
SC & $8.2^{\mathrm{b}} \pm 0.17$ & $0.819^{\mathrm{cd}} \pm 0.05$ & $0.328^{\mathrm{d}} \pm 0.001$ & $10.02^{\mathrm{b}} \pm 0.44$ \\
Fresh & 5.3 & 0.324 & 0.951 & 16.34 \\
CV & 1.8 & 3.2 & 0.72 & 4.21 \\
Lsd & 0.45 & 0.07 & 0.007 & 1.18 \\
\hline
\end{tabular}

Means with the same letter are not significantly different $(p \geq 0.05)$ according to Tukey's (significant difference) test.

\section{Discussion}

5.1. Quality of Dried Tomato Slices. The observed decrease in the lycopene content of tomatoes after drying in this experimental work is in agreement with $[10,15,26]$ who studied tomato. It was reported that thermal processing of tomatoes into paste results in decreases in the lycopene concentration of $9-28 \%$ and longer processing may also result in increased losses [27]. Mayeaux et al. [28] also reported about $75 \%$ and $70 \%$ of lycopene loss during drying of tomatoes for $2 \mathrm{~min}$ at temperatures of $165 \mathrm{C}$ and $145 \mathrm{C}$, respectively. This lycopene content decrease observed in the dried tomato could be due to the oxidation of the lycopene during the drying process [29]. 
TABLE 3: Change in color values of dried tomato slices pretreated with different predrying treatments.

\begin{tabular}{lcccc}
\hline Predrying treatments & $\Delta E$ & $\Delta$ chroma & $\Delta h^{0}$ & $\Delta L$ \\
\hline AA & 16.61 & 4.88 & 5.7 & 14.69 \\
CA & 11.37 & 6.44 & -2.22 & 5.35 \\
SC & 18.387 & 11.77 & 5.05 & 13.53 \\
CC & 17.837 & 8.13 & 9.92 & 15.10 \\
CO & 17.68 & 1.86 & 5.07 & 17.38 \\
\hline
\end{tabular}

$\Delta L$ Lo- $L ; \Delta E$ total color difference; $\Delta \mathrm{h}^{0} h^{0} 0-h^{0} ; \Delta$ chroma chroma fresh sample-chroma dry sample. $L_{0}$ brightness of the fresh sample; $L$ brightness of the dry sample; $h_{0}^{0}$ : hue angle of the fresh sample; $h^{0}$ hue angle of the dry sample. $\Delta$ chroma change in chroma; $\Delta h$ change in hue; $\Delta L$ change in lightness. (All the changes were measured relative to the fresh samples, i.e., fresh-dry.)

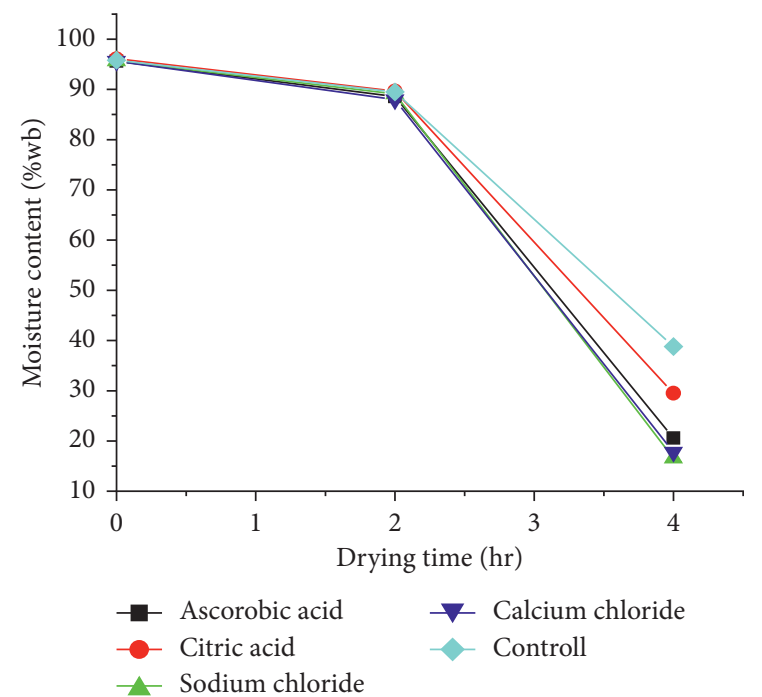

Figure 4: Moisture content (\%wb) of pretreated tomato slices versus drying time (hr) during drying in the twin layer solar tunnel dryer.

The observed maximum retention of lycopene for the pretreated tomato samples was also similar to results previously reported by different researchers on the lycopene retention of pretreated tomatoes during drying. Farooq et al. [15] reported a higher lycopene content for tomato slices pretreated with $0.5 \%$ ascorbic acid $+0.5 \%$ citric acid than the non-pretreated samples. Mwende et al. [10] found higher retention of lycopene in $0.5 \%$ calcium chloride-pretreated samples than the untreated control during oven drying of different varieties of tomato slices at $50^{\circ} \mathrm{C}, 60^{\circ} \mathrm{C}$, and $70^{\circ} \mathrm{C}$ to a final moisture content of $13 \%$ (wb). Hameed et al. [26] also reported higher retention of lycopene for $1 \%$ sodium chloride-pretreated samples than the untreated ones during sun, solar tunnel, and cabinet drying of two varieties of tomato slices. This higher retention in the lycopene content of pretreated tomatoes indicates that predrying treatments can minimize the oxidation of lycopene during drying.

The observed vitamin $\mathrm{C}$ decrease after drying in this work is in agreement with $[23,30]$ who reported a significant vitamin $\mathrm{C}$ decrease in tomatoes after thermal processing. High lycopene retention obtained for pretreated tomato slices in this work is in agreement with the findings of other researchers. High retention of vitamin $\mathrm{C}$ was reported by Farooq et al. [15] for tomato slices pretreated with $0.5 \%$ ascorbic acid $+0.5 \%$ citric acid than the non-pretreated samples. Acid pretreatment is frequently used to improve the product quality through inactivating enzymes, enhancing pigment stability, and modifying the texture of agro-products during drying [11]. In addition, it is reported that salts of calcium and sodium have been tested to inhibit polyphenol oxidase [31]. The result from this work indicates that these predrying treatments can be used to minimize the oxidation of vitamin $\mathrm{C}$ during twin layer solar tunnel drying of tomato.

The degradation of the total phenolic content of tomatoes after drying in this experiment is in agreement with [10] who studied tomato. Similar results were also reported by Nurkhoeriyati et al. [32] who studied on celeriac and by Madrau et al. [33] who studied on apricot. The data reported by Ahmed et al. [34, 35] was also in agreement with this finding that heat processing affects the stability of polyphenols due to chemical degradation. The higher retention of the total phenolic content in pretreated samples than untreated samples observed in this work may be due to the ability of citric acid, sodium chloride, and ascorbic acid to retard oxidative reactions during drying.

Similar results were also obtained by [10] who reported higher retention of total phenolic content for $0.5 \%$ calcium chloride-pretreated samples than the untreated samples after oven drying of tomato at $50^{\circ} \mathrm{C}, 60^{\circ} \mathrm{C}$, and $70^{\circ} \mathrm{C}$. It is reported that salts of calcium and sodium have been tested to inhibit polyphenol oxidase [31]. Ascorbic acid reduces polyphenol oxidases browning by reducing $o$-quinones back to phenol compounds before they form brown pigments [36]. Citric acid, as an organic acid, is the most commonly used antidarkening agent and a texture-modifier of fruits and vegetables [37].

The increase in the TSS value obtained after drying of tomatoes in this work is similar to the findings of Yusufe et al. [38] and Das Purkayastha et al. [23] who reported an increase in the TSS of tomato slices after oven drying at different temperatures. In this work, the higher total soluble solids obtained for pretreated samples than the untreated ones are similar to the report of Owureku-Asare et al. [39] who find higher total soluble solids in the samples pretreated with $0.5 \%$ sodium metabisulphite and $0.1 \%$ ascorbic acid $+0.1 \%$ citric acid as compared to the control samples during tomato drying. And this may be due to the hindrance of enzymatic and nonenzymatic browning during drying in the existence of these pretreatments. The lower TSS of the untreated samples may be due to the Maillard reaction.

The titratable acidity measures the total acid concentration in foods. Food acids are usually organic acids, with malic, tartaric, lactic, acetic, and citric acid, being the most common [23]. Different researchers [13, 23, 38] reported an increase in the titratable acidity of tomatoes subjected to drying similar to the findings of this work. This increase in titratable acidity may be due to the formation of different organic acids that can be associated with the tendency of the fall of the $\mathrm{pH}$ of the dried tomatoes [13]. 
At water activity more than 0.7 , the quality of food products is mainly affected by moulds, yeasts, bacteria, and other microorganisms [40], and foods with water activity in the range of $0.5-0.8$ are more susceptible to nonenzymatic browning. Water activity values under 0.2 result in lipid oxidation [41]. But the water activity result obtained in this work $(0.328-0.384)$ is in the safe range from microbial growth, enzymatic and nonenzymatic browning, and lipid oxidation for all treatments.

The decrease in TSS/TA observed in this experiment may be due to an increase in titratable acidity and a decrease in TSS after drying. High TSS with reasonable amount of TA may contribute to the sweetness and flavor of dried product [42]. TSS/TA values higher than 10 indicate optimum combination between sugar and acidity, being correlated with mild flavor [13]. All of the pretreated samples showed TSS/TA ratio of around 10, which indicated that tomatoes with mild flavor can be obtained by pretreating tomato slices before drying.

Color is one of the most important quality attributes of foods as it is critical in the acceptance of food products by consumers [11]. $\Delta E$ is not sufficient to define which color parameters $\left(L^{*}, a^{*}\right.$, and/or $\left.b^{*}\right)$ caused this [43]. During thermal processing, color change in tomato occurs due to nonenzymatic browning, [44, 45] lycopene degradation, and change of all-trans-lycopene to cis-form [46]. Decrease in the $L$ value of the dried tomatoes in this work is in agreement with findings of Mwende et al. [10] for oven-dried tomatoes dried at $50^{\circ} \mathrm{C}, 60^{\circ} \mathrm{C}$, and $70^{\circ} \mathrm{C}$. A similar decrease in the $L$ value was also reported by Ashebir et al. [47] for different cultivars of tomato after hot air drying. The small decrease in the $L$ value of pretreated samples in this work may be due to the protective effect of the pretreatments from oxidation, and the higher decrease in the $L$ value of the control (untreated) samples may be due to enzymatic and nonenzymatic reactions that occur during heat processing. The decrease in hue angle $\left(h^{0}\right)$ observed in this work may be due to the higher retention of the lycopene content of the slices pretreated with calcium chloride and sodium chloride. Chroma reflects color purity or saturation. It is an expression of the saturation or purity of a single color (different colors may have the same chroma values) [48]. Similar observations were reported by Joshi et al. [49] that samples pretreated with calcium chloride and sodium chloride had better visual appeal than those pretreated with ascorbic acid for tomato slices dried in a cabinet air dryer.

5.2. Drying Curve of Moisture Content (\%wb) versus Time. The higher water removal rate obtained in pretreated samples than the untreated control in this work is in agreement with earlier observations by different researchers. Mozumder et al. [1] reported increased water removal of tomato slices pretreated with $1 \%$ calcium chloride than untreated control samples. Lewicki and Michaluk [50] reported smaller resistance to mass transfer and increased drying rate for convective drying of tomatoes pretreated with $1 \%$ calcium chloride. Similar observations were reported by [51] that pretreatment with $\mathrm{CaCl}_{2}$ and $\mathrm{NaCl}$ increased water removal and moisture mobility in tomato slices during drying.

\section{Conclusions}

Effects of predrying treatments on physicochemical quality and drying kinetics of twin-layer-solar-tunnel-dried tomato slices had been investigated in this study, and the following conclusions can be drawn. Total phenolic compounds and vitamin $\mathrm{C}$ were best retained by ascorbic acid and citric acidtreated samples. High lycopene retention was obtained in sodium chloride followed by calcium chloride, ascorbic acid, and citric acid-treated samples than the control ones. The highest sugar/acid ratio was found in samples pretreated with ascorbic acid followed by sodium chloride, calcium chloride, and citric acid. All the pretreated tomato samples had a good overall color value than the control, and the degree of darkening was least in the pretreated samples as follows: citric acid < sodium chloride $<$ ascorbic acid$<$ calcium chloride $<$ control. Predrying treatments significantly increased the moisture removal rate of dried tomato samples as compared to the control. Sodium chloride followed by calcium chloride increased the water removal rate compared to the other pretreatments during drying. The result, therefore, showed that using $0.5 \%$ citric acid, $0.5 \%$ sodium chloride, $0.5 \%$ ascorbic acid, and $0.5 \%$ calcium chloride as predrying treatments in twin layer solar tunnel drying of tomato slices can control undesirable quality changes that occur during tomato drying and helps to minimize the drying time.

\section{Abbreviations}

$\begin{array}{ll}\%: & \text { Percentage } \\ \% \text { wb: } & \text { Percent of wet basis } \\ { }^{\circ} \mathrm{Brix}: & \text { Degrees Brix } \\ { }^{\circ} \mathrm{C}: & \text { Degree Celsius } \\ a: & \text { Hue range of the colors red }(+) \text { and green }(-) \text { for } \\ & \text { dry sample } \\ \mathrm{a} 0: & \text { Hue range of the colors red }(+) \text { and green }(--) \\ & \text { for fresh sample } \\ \text { ANOVA: } & \text { Analysis of variance } \\ \text { AOAC: } & \text { Association of analytical chemists } \\ b: & \text { Hue range of colors yellow }(+) \text { and blue }(-) \text { for } \\ & \text { dry sample } \\ b_{0}: & \text { Hue range of colors yellow }(+) \text { and blue }(-) \text { for } \\ \mathrm{C}_{6} \mathrm{H}_{8} \mathrm{O}_{6}: & \text { fresh sample } \\ \mathrm{C}_{6} \mathrm{H}_{8} \mathrm{O}_{7}: & \text { Citric acid } \\ \mathrm{CaCl}{ }_{2}: & \text { Calcium chloride } \\ \mathrm{CRD}: & \text { Completely randomized design } \\ \mathrm{DM}: & \text { Dry matter } \\ \mathrm{g} \mathrm{DM}: & \text { Gram of dry matter } \\ \mathrm{g} / \mathrm{mole}: & \text { Gram per mole } \\ \mathrm{g}: & \text { Gram } \\ \mathrm{GA}: & \text { Gallic acid } \\ \mathrm{GAE}: & \text { Gallic acid equivalent } \\ \mathrm{gdw}: & \text { Gram of dry weight } \\ \mathrm{H}_{2} \mathrm{O}: & \text { Water }\end{array}$


HOAc: $\quad$ Acetic acid

$\mathrm{HPO}_{3}$ : Metaphosphoric acid

L: $\quad$ Brightness of the dry sample

$L_{0}: \quad$ Brightness of the fresh sample

meq: $\quad$ Milliequivalent

mg: $\quad$ Milligram

ml: $\quad$ Milliliter

N: Normal

$\mathrm{NaCl}: \quad$ Sodium chloride

$\mathrm{NaHCO}_{3}$ : Sodium bicarbonate

RELOAD: Reduction of postharvest losses and value addition in East African food value chain

$\Delta E: \quad$ Total color change.

\section{Data Availability}

The data used to report these results are available from the corresponding author upon request.

\section{Conflicts of Interest}

The authors declare that there are no conflicts of interest.

\section{Acknowledgments}

The authors acknowledge RELOAD (Reduction of Postharvest Losses and Value Addition in East African Food Value Chain) project and the Department of Postharvest Management, Jimma University College of Agriculture and Veterinary Medicine, for all given support. This work was funded by RELOAD (Reduction of Postharvest Losses and Value Addition in East African Food Value Chain) (BMBF/ BMZ 031A247A-D).

\section{References}

[1] N. Mozumder, M. Rahman, M. Kamal, A. Mustafa, and M. Rahman, "Effects of pre-drying chemical treatments on quality of cabinet dried tomato powder," Journal of Environmental Science and Natural Resources, vol. 5, no. 1, pp. 253-265, 2012.

[2] F. Brasesco, D. Asgedom, and G. Casari, Strategic Analysis and Intervention Plan for Fresh and Industrial Tomato in the AgroCommodities Procurement Zone of the Pilot Integrated AgroIndustrial Park in Central-Eastern Oromia, Ethiopia, Food and Agriculture Organization of the United Nations (FAO), Rome, Italy, 2019.

[3] Faostat. (2018). http://www.fao.org/faostat/en/\#data/QC/ visualize.

[4] B. Emana, V. Afari-Sefa, N. Nenguwo, A. Ayana, D. Kebede, and H. Mohammed, "Characterization of pre- and postharvest losses of tomato supply chain in Ethiopia," Agriculture \& Food Security, vol. 6, no. 1, p. 3, 2017.

[5] V. N. Hegde, V. S. Hosur, S. K. Rathod, P. A. Harsoor, and K. B. Narayana, "Design, fabrication and performance evaluation of solar dryer for banana," Energy, Sustainability and Society, vol. 5, no. 1, p. 23, 2015.

[6] M. Puri, How Access to Energy Can Influence Food Losses. A Brief Overview, FAO, Rome, Italy, 2016.

[7] L. T. Dufera, W. Hofacker, A. Esper, and O. Hensel, "Experimental evaluation of drying kinetics of tomato
(Lycopersicum Esculentum L.) slices in twin layer solar tunnel dryer," Energy for Sustainable Development, vol. 61, pp. 241-250, 2021.

[8] L. T. Dufera, W. Hofacker, A. Esper, and O. Hensel, "Physicochemical quality of twin layer solar tunnel dried tomato slices," Heliyon, vol. 7, no. 5, p. e07127, 2021.

[9] D. M. C. C. Gunathilake, D. P. Senanayaka, G. Adiletta, and W. Senadeera, Drying of Agricultural crops.inAdvances in Agricultural Machinery and Technologies, CRC Press, Boca Raton, FL, USA, 2018.

[10] R. Mwende, W. Owino, and S. Imathiu, "Effects of pretreatment during drying on the antioxidant properties and color of selected tomato varieties," Food Sciences and $\mathrm{Nu}$ trition, vol. 6, no. 2, pp. 503-511, 2018.

[11] L.-Z. Deng, A. S. Mujumdar, Q. Zhang et al., "Chemical and physical pretreatments of fruits and vegetables: effects on drying characteristics and quality attributes-a comprehensive review," Critical Reviews in Food Science and Nutrition, vol. 59, no. 9, pp. 1408-1432, 2019.

[12] V. Belessiotis and E. Delyannis, "Solar drying," Solar Energy, vol. 85, no. 8, pp. 1665-1691, 2011.

[13] W. C. D. Abreu, M. D. F. P. Barcelos, E. P. Silva, and E. V. D. B. V. Boas, "Physical and chemical characteristics and lycopene retention of dried tomatoes subjected to different pre-treatments," Revista Do Instituto Adolfo Lutz, vol. 70, no. 2, pp. 168-174, 2011.

[14] G. Latapi and D. M. Barrett, "Influence of pre-drying treatments on quality and safety of sun-dried tomatoes. Part I: use of steam blanching, boiling brine blanching, and dips in salt or sodium metabisulfite," Journal of Food Science, vol. 71, no. 1, 2006.

[15] S. Farooq, S. Rather, A. Gull et al., "Physicochemical and nutraceutical properties of tomato powder as affected by pretreatments, drying methods, and storage period," International Journal of Food Properties, vol. 23, no. 1, pp. 797-808, 2020.

[16] S. S. Nielsen, Food Analysis Laboratory Manual, S. S. Nielsen, Ed., , Springer, New York, NY, USA, 2nd edition, 2010.

[17] T. Suwanaruang, "Analyzing lycopene content in fruits," Agriculture and Agricultural Science Procedia, vol. 11, pp. 46-48, 2016.

[18] Aoac, "Vitamin C in vitamin preparations and Juices.Official method 967.21," in AOAC Official Methods of Analysis, Association of Official Analytical Chemists, Gaithersburg, MD, USA, 18th edition, 2005.

[19] V. L. Singleton, R. Orthofer, and R. M. Lamuela-Raventós, "Analysis of total phenols and other oxidation substrates and antioxidants by means of folin-ciocalteu reagent," Oxidants and Antioxidants Part A, vol. 299, pp. 152-178, 1999.

[20] G. D. Sadler and P. A. Murphy, "pH and titratable acidity," Food Science Texts Series, Springer, Boston, MA, USA, 2010.

[21] A. Tefera, T. Seyoum, and K. Woldetsadik, "Effect of disinfection, packaging, and storage environment on the shelf life of mango," Biosystems Engineering, vol. 96, no. 2, pp. 201-212, 2007.

[22] R. E. Wrolstad and D. E. Smith, "Color analysis," in Food Analysis, Food Science Text Series, S. S. Nielson, Ed., Springer International Publishing AG, Berlin, Germany, 2017.

[23] M. Das Purkayastha, A. Nath, B. C. Deka, and C. L. Mahanta, "Thin layer drying of tomato slices," Journal of Food Science and Technology, vol. 50, no. 4, pp. 642-653, 2013.

[24] K. A. Gomez, K. A. Gomez, and A. A. Gomez, Statistical Procedures for Agricultural Research, John Wiley \& Sons, Hoboken, NJ, USA, 1984. 
[25] P. H. S. Santos and M. A. Silva, "Retention of vitamin C in drying processes of fruits and vegetables-A review," Drying Technology, vol. 26, no. 12, pp. 1421-1437, 2008.

[26] O. B. Hameed, H. Ahsan, M. Bhat, N. Nissar, N. Jan, and M. Reshi, "Influence of pretreatments and different drying methods on lycopene content of dried tomato," Indian Journal of Ecology, vol. 43, 2016.

[27] G. R. Takeoka, L. Dao, S. Flessa et al., "Processing effects on lycopene content and antioxidant activity of tomatoes," Journal of Agricultural and Food Chemistry, vol. 49, no. 8, pp. 3713-3717, 2001.

[28] M. Mayeaux, Z. Xu, J. M. King, and W. Prinyawiwatkul, "Effects of cooking conditions on the lycopene content in tomatoes," Journal of Food Science, vol. 71, no. 8, pp. C461-C464, 2006.

[29] W. M. Abdel-Aleem, S. M. Abdel-Hameed, and S. S. Latif, "Influence of pre-drying treatments on the quality attributes and storage stability of tomatoes," Minia Journal of Agriculture Research and Development, vol. 35, 2015.

[30] K. Jacob, F. J. Garcia-Alonso, G. Ros, and M. J. Periago, "Stability of carotenoids, phenolic compounds, ascorbic acid and antioxidant capacity of tomatoes during thermal processing," Archivos Latinoamericanos de Nutricion, vol. 60, no. 2, pp. 192-8, 2010.

[31] O. Martin-Belloso and R. S. Fortuny, Advances in Fresh-Cut Fruits and Vegetables Processing, CRC Press, Boca Raton, FL, USA, 2010.

[32] T. Nurkhoeriyati, B. Kulig, B. Sturm, and O. Hensel, "The effect of pre-drying treatment and drying conditions on quality and energy consumption of hot air-dried celeriac slices: optimisation," Foods, vol. 10, no. 8, p. 1758, 2021.

[33] M. A. Madrau, A. Piscopo, A. M. Sanguinetti et al., "Effect of drying temperature on polyphenolic content and antioxidant activity of apricots," European Food Research and Technology, vol. 228, no. 3, pp. 441-448, 2009.

[34] M. Ahmed, M. S. Akter, and J.-B. Eun, "Peeling, drying temperatures, and sulphite-treatment affect physicochemical properties and nutritional quality of sweet potato flour," Food Chemistry, vol. 121, no. 1, pp. 112-118, 2010.

[35] C. G. Kuyu, Y. B. Tola, A. Mohammed, and H. S. Ramaswamy, "Determination of citric acid pretreatment effect on nutrient content, bioactive components, and total antioxidant capacity of dried sweet potato flour," Food Sciences and Nutrition, vol. 6, no. 6, pp. 1724-1733, 2018.

[36] J. E. Lozano: 2006. Inhibition and Control of Browning. Fruit Manufacturing: Scientific Basis, Engineering Properties, and Deteriorative Reactions of Technological Importance.

[37] B. Hiranvarachat, S. Devahastin, and N. Chiewchan, "Effects of acid pretreatments on some physicochemical properties of carrot undergoing hot air drying," Food and Bioproducts Processing, vol. 89, no. 2, pp. 116-127, 2011.

[38] M. Yusufe, A. Mohammed, and N. Satheesh, "Effect of duration and drying temperature on characteristics of dried tomato (Lycopersicon esculentum L.) cochoro variety," Acta Universitatis Cibiniensis. Series E: Food Technology, vol. 21, no. 1, pp. 41-50, 2017.

[39] M. Owureku-Asare, J. Agyei-Amponsah, F. Saalia, L. Alfaro, L. A. Espinoza-Rodezno, and S. Sathivel, "Effect of pretreatment on physicochemical quality characteristics of a dried tomato (Lycopersicon esculentum)," African Journal of Food Science, vol. 8, no. 5, pp. 253-259, 2014.

[40] S. Vijayan, T. V. Arjunan, and A. Kumar, Fundamental concepts of drying, Solar Drying Technology, pp. 3-38, Springer, Singapore, 2009.
[41] R. D. P. F. Guiné, M. J. Barroca, H. Weingartemann, and R. Gretzmacher, Drying kinetics in solar drying, Solar Drying Technology, Prakash and A. Kumar, Eds., pp. 317-355, Springer, Singapore, 2017.

[42] A. Dereje, K. Jezik, H. Weingartemann, and R. Gretzmacher, "Change in color and other fruit quality characteristics of tomato cultivars after hot-air drying at low final-moisture content," International Journal of Food Sciences \& Nutrition, vol. 60, no. S7, pp. 308-315, 2009.

[43] Anonymous, "CIE $L * a * b$ color scale. Applications NoteInsight on Color," Hunter Lab, vol. 8, no. 7, pp. 1-4, 1996.

[44] S. Cernîsev, "Effects of conventional and multistage drying processing on nonenzymatic browning in tomato," Journal of Food Engineering, vol. 96, no. 1, pp. 114-118, 2010.

[45] C.-H. Chang, H.-Y. Lin, C.-Y. Chang, and Y.-C. Liu, "Comparisons on the antioxidant properties of fresh, freezedried and hot-air-dried tomatoes," Journal of Food Engineering, vol. 77, no. 3, pp. 478-485, 2006.

[46] K. Coelho, B. R. Costa, and L. A. de Almeida Pinto, "Evaluation of lycopene loss and colour values in convective drying of tomato by surface response methodology," International Journal of Food Engineering, vol. 9, no. 2, pp. 233-238, 2006.

[47] D. Ashebir, K. Jezik, H. Weingartemann, and R. Gretzmacher, "Change in color and other fruit quality characteristics of tomato cultivars after hot-air drying at low final-moisture content," International Journal of Food Sciences \& Nutrition, vol. 60, no. 7, pp. 308-315, 2009.

[48] L. López Camelo and P. A. Gómez, "Comparison of color indexes for tomato ripening," Horticultura Brasileira, vol. 22, no. 3, pp. 534-537, 2004.

[49] N. Joshi, Y. Gariepy, and G. V. Raghavan, "Comparative evaluation of different pretreatments on tomato slices dried in a cabinet air drier," International Journal of Food Engineering, vol. 4, no. 7, 2008.

[50] P. P. Lewicki and E. Michaluk, "Drying of tomato pretreated with calcium," Drying Technology, vol. 22, no. 8, pp. 1813-1827, 2004.

[51] S. Mohseni and R. A. Ghavidel, "Effect of pre-drying treatments on quality characteristics of dehydrated tomato slices," World Academy of Science, Engineering and Technology, vol. 59, pp. 2205-2215, 2011. 